\title{
TU/e EmonOWEN

\section{Aggregation of component-based grid-feeding DER and load models for simulation of microgrid islanding transients}

\section{Citation for published version (APA):}

Roos, M. H., Nguyen, P. H., Morren, J., \& Slootweg, J. G. (2020). Aggregation of component-based grid-feeding DER and load models for simulation of microgrid islanding transients. Electric Power Systems Research, 189, [106759]. https://doi.org/10.1016/j.epsr.2020.106759

DOI:

10.1016/j.epsr.2020.106759

Document status and date:

Published: 01/12/2020

\section{Document Version:}

Author's version before peer-review

\section{Please check the document version of this publication:}

- A submitted manuscript is the version of the article upon submission and before peer-review. There can be important differences between the submitted version and the official published version of record. People interested in the research are advised to contact the author for the final version of the publication, or visit the $\mathrm{DOI}$ to the publisher's website.

- The final author version and the galley proof are versions of the publication after peer review.

- The final published version features the final layout of the paper including the volume, issue and page numbers.

Link to publication

\section{General rights}

Copyright and moral rights for the publications made accessible in the public portal are retained by the authors and/or other copyright owners and it is a condition of accessing publications that users recognise and abide by the legal requirements associated with these rights.

- Users may download and print one copy of any publication from the public portal for the purpose of private study or research.

- You may not further distribute the material or use it for any profit-making activity or commercial gain

- You may freely distribute the URL identifying the publication in the public portal.

If the publication is distributed under the terms of Article 25fa of the Dutch Copyright Act, indicated by the "Taverne" license above, please follow below link for the End User Agreement:

www.tue.nl/taverne

Take down policy

If you believe that this document breaches copyright please contact us at:

openaccess@tue.nl

providing details and we will investigate your claim. 


\title{
Aggregation of Component-Based Grid-Feeding DER and Load Models for Simulation of Microgrid Islanding Transients
}

\author{
M.H. Roos*, P.H. Nguyen*‡, J. Morren*†, J.G. Slootweg*† \\ ${ }^{*}$ Department of Electrical Engineering \\ Eindhoven University of Technology, Eindhoven, the Netherlands \\ Email:m.h.roos@tue.nl \\ ${ }^{\dagger}$ Asset Management, \\ Enexis Netbeheer, 's-Hertogenbosch, the Netherlands \\ ${ }^{\ddagger}$ Sustainable Energy Systems Group, \\ Luxembourg Institute of Science and Technology, Belvaux, Luxemburg
}

\begin{abstract}
The reliability of distribution networks can be improved by islanding of part of the network when a short-circuit fault occurs. The voltage and frequency stability during transient can be evaluated with time-domain simulations using componentbased DER and load models. However, simulations with this type of models have a relatively high computational burden which constrains periodical stability analysis of microgrids. This paper proposes an aggregation methodology which significantly decreases the computation time of fault-initiated islanding simulations with component-based models, while maintaining the nonlinear dynamics. The methodology is first validated by directly comparing the original and equivalent models during large voltage and frequency transients. Secondly, a fault-initiated islanding case study of a residential distribution network is performed. For both validations, a sensitivity analysis of model parameters and voltage variations is performed. The results indicate the methodology preserves the dynamics of DERs and loads, while significantly reducing the computational time.
\end{abstract}

Index Terms-Dynamic equivalent model, microgrids, islanding, distributed generation, power system transients.

\section{INTRODUCTION}

The increasing societal dependence on electrical energy and the occurrence of natural disasters fuels the need for more reliable and resilient power (distribution) networks [1]. The reliability of distribution networks can be increased by fault-initiated islanding (FII), which forms islanded microgrids in case of a contingency such as a short-circuit fault [2], [3]. During the FII transient, the voltage and frequency can significantly deviate from their nominal values due to interactions between the phase-locked loop of distributed energy resources (DERs) and the load [4], and the lack of voltage and frequency control. Therefore the stability of the microgrids should be evaluated to enable FII, especially during and right after the FII transient [5]. The stability analysis should be

This work has received funding from the European Union's Horizon 2020 research and innovation program under grant agreement $\mathrm{N}^{\circ} 773717$. performed periodically due to the variability of generation, network structure and load in microgrids.

To analyze the stability with time-domain simulations, accurate DER and load models are required which represent the nonlinear behavior during transients. The dynamics of different subsystems are strongly coupled in microgrids [6] requiring comprehensive DER and load models. Componentbased models can model the behavior of DERs and load devices with a very high level of detail, accurately describing the electrical, mechanical, controllers and protection systems [7], [8]. Although component-based models can describe the behavior of the DERs and loads with high accuracy, these models increase the required computation time which constrains the ability to periodically perform FII stability analysis.

The computation time can be reduced by aggregation of the DER and load models. Three main methodologies for load aggregation have been described in the literature: modal analysis, coherency based aggregation and system identification [8]. System identification and modal analysis techniques are not suitable for detailed component-based models. System identification techniques are based on measurements to generate models as opposed to device components. Modal analysis requires linear models which neglects important nonlinear dynamics.

During coherency based aggregation, models with similar dynamics are replaced by an equivalent model. Coherency based methods have been mostly used for aggregation of synchronous and induction machines [9]-[11]. Aggregation of power electronic load models has been performed by [12], [13], however until now only the steady-state behavior of these aggregated models have been validated.

In this paper, a component-based DER and load model aggregation methodology is proposed which reduces the computation time of simulations of FII microgrids significantly, while preserving the dynamic behavior for accurate stability analysis. The methodology is validated by direct comparison between the original and aggregated models, and a FII case 
study in a modified version of the CIGRE European LV residential distribution benchmark network.

The contributions of this paper are:

1) The aggregation methodology for component-based DER and load models which decreases computation time of FII microgrid simulations while maintaining accurate dynamics.

2) Verification of the accuracy of component-based load and DER device equivalencing under parameter variation and voltage differences.

3) Verification of the accuracy and reduction of computational burden of the methodology with a FII case study under different network impedance, and DER and load models parameter variations.

In the next section the aggregation methodology is described, the numerical validation of the methodology is discussed in section III, the results are shown in section IV and discussed in section V, and finally in section VI conclusions are given.

\section{Aggregation Methodology}

The methodology consists of several steps to transform a network consisting of nodes and branches into a reduced network with a common node to which the grid-feeding DERs and load devices are connected. An overview of the aggregation methodology is shown in Fig.1. First, the network nodes are classified based on the connected DERs and load devices, which are classified based on the different device types. Second, a Kron reduction is applied to eliminate the interior and empty nodes while maintaining the boundary and device nodes. Third, a common node is created to which all gridfeeding DERs and detailed load models are connected instead of the network nodes. The power weighted average (PWA) of the devices is used to create equivalent current sources at the network nodes and an equivalent voltage source at the common node. Final, dynamic equivalent models are created for each type of device based on the device classification.

\section{A. Classification}

Network nodes are classified into four categories: boundary, device, interior and empty. Nodes to which the point of common coupling (PCC) and/or grid-supporting DERs are connected are classified as boundary nodes. Nodes to which grid-feeding DERs and/or detailed load models are connected are device nodes. Nodes to which only constant impedance loads are connected are interior nodes, and nodes without DERs or load devices are empty nodes.

Devices are classified into different categories based on the type of device to cluster devices with similar structure to allow the development of accurate equivalent models. Additionally, classification can be performed based on electrical, mechanical, controller, and protection system parameters. A larger set of classes can increase accuracy, however this results in more equivalent models, increasing the computation time.

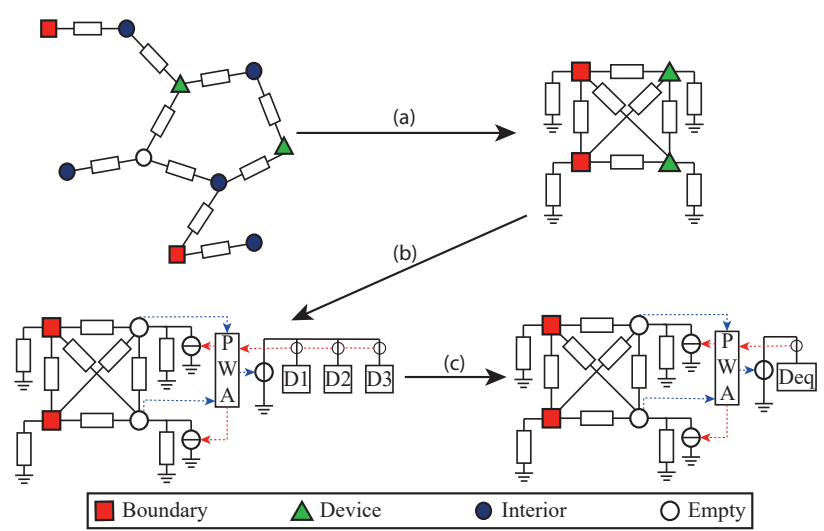

Fig. 1: Overview of the aggregation methodology. (a): Kron reduction of interior and empty nodes of original network. (b): Creation of common node with power weighted average voltage. (c): Equivalencing of DER and load devices of same type. PWA: Power weighted average, Deq: dynamic equivalent of devices $D 1, D 2$ and $D 3$.

\section{B. Network Reduction}

1) Kron reduction: Kron reduction is a network reduction methodology which reduces the number of nodes and constant impedance loads in the network. The boundary and device nodes are critical for voltage stability analysis as they contain all detailed, nonlinear models. Therefore, these nodes are preserved and Kron reduction is utilized to eliminate interior and empty nodes. Since the load connected to boundary and detailed load nodes does not impact the Kron equivalent network impedances, the DERs and detailed loads are neglected during Kron network reduction.

To perform Kron reduction, the network admittance matrix $Y_{N e t}$ is build as described by equation 1 . Where $N$ is a set of boundary and detailed load nodes, $M$ is a set of interior and empty nodes, $K$ is a set of detailed load nodes, $P$ is a set of device types and $Q$ is a set of devices of each type. Matrices $Y_{N N}, Y_{N M}$ and $Y_{M M}$ contain the node admittance and admittance between nodes of set $N, N$ and $M$, and $M$ respectively.

$$
Y_{N e t}=\left[\begin{array}{ll}
Y_{N N} & Y_{N M} \\
Y_{N M}^{T} & Y_{M M}
\end{array}\right]
$$

The Kron reduced admittance matrix is determined by using equation 2 [14].

$$
Y_{k r o n}=Y_{N N}-Y_{N M} Y_{M M}^{-1} Y_{N M}^{T}
$$

2) Creation of common node: Before equivalent models can be developed for each type of device, the models should be connected to the same node. Therefore, a common node is created to which all grid-feeding DER and detailed load models are connected. The common node is fed by a voltage source which provides the PWA of the voltage of the device nodes as shown in Fig. 1. The device nodes are replaced by empty nodes with current sources which absorb or inject the PWA of the current of the device models connected to the common node. 


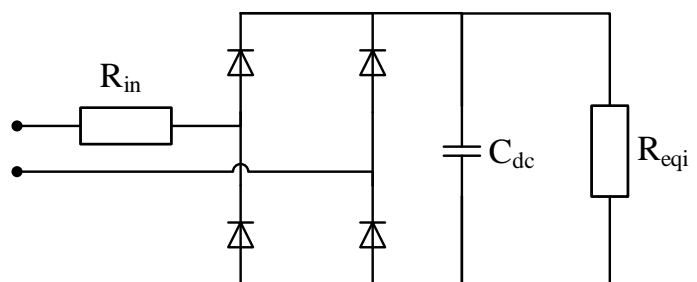

Fig. 2: Diagram of compact fluorescent lighting load device.

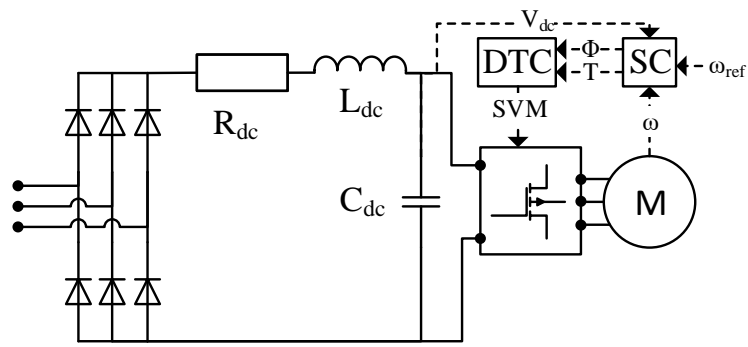

Fig. 3: Diagram of variable frequency drive load device.

The PWA of the voltage $\left(V_{e q}\right)$ is determined by equation 3 , while the PWA of the current injected at node $k\left(I_{e q}^{k}\right)$ is determined by equation 4 . Where $V_{k}$ is the voltage at node $k, S_{k}$ is the total apparent power absorbed by the devices at node $k, S_{p, k}$ is the total apparent power absorbed by devices of type $p$ connected to node $k$.

$$
\begin{gathered}
V_{e q}=\sum_{k=1}^{K} V_{k} \frac{\left|S_{k}\right|}{\sum_{k=1}^{K}\left|S_{k}\right|} \\
I_{e q}^{k}=\sum_{p=1}^{P} \frac{\left|S_{p, k}\right|}{\sum_{k=1}^{K}\left|S_{p, k}\right|} \sum_{q=1}^{Q} I_{p, q}
\end{gathered}
$$

\section{Device equivalencing}

As shown in Figs. 2, 3 and 4, component-based models of DER and load devices consist of several components. By scaling the parameter values of the components, the models can be scaled to different power ratings with equal dynamics. Since two parallel devices with identical parameters can be represented as a single device with two times the power rating, this concept is fundamental for the device equivalencing methodology. For example, a constant impedance load can be scaled to different power ratings by changing the impedance. Likewise, two parallel constant impedance loads can be represented by a single constant impedance load with the equivalent impedance.

This paper considers electrical, mechanical, controller and protection system parameters for device equivalencing. The remainder of this section describes how these parameters are determined. Note that as the models in this paper are nonlinear, the accuracy of the equivalent model depends on how similar the parameters of the original devices are. When two devices have very different parameters e.g. mechanical loads with similar power ratings and a large inertia mismatch,

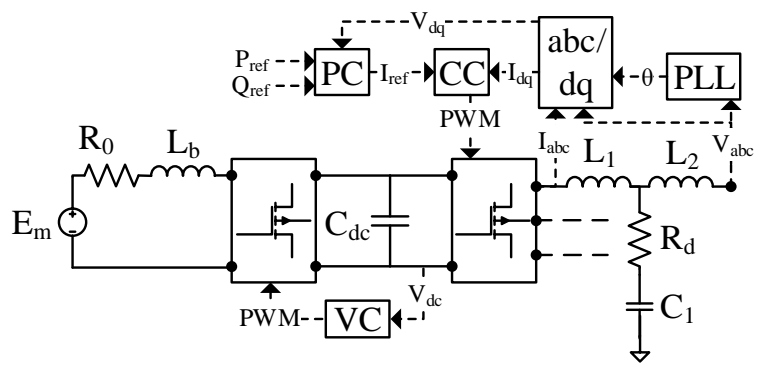

Fig. 4: Diagram of three phase photovoltaic DER.

these devices should be aggregated into multiple models as discussed in section II-A.

1) Electrical parameters: The electrical parameters are determined according to the parallel impedance. Resistance $R_{e q}$, impedance $L_{e q}$ and capacitance $C_{e q}$ values are determined with equation 5 where $D$ is the number of parallel devices.

$$
R_{e q}=\frac{1}{\sum_{i=1}^{D} \frac{1}{R_{i}}}, \quad L_{e q}=\frac{1}{\sum_{i=1}^{D} \frac{1}{L_{i}}}, \quad C_{e q}=\sum_{i=1}^{D} C_{i}
$$

2) Mechanical load parameters: The equivalent inertia $J_{e q}$, friction $F_{e q}$ and torque $T_{e q}$ are equal to the sum of the inertia, friction and torque of the devices as described by equation 6 .

$$
J_{e q}=\sum_{i=1}^{D} J_{i}, \quad F_{e q}=\sum_{i=1}^{D} F_{i}, \quad T_{e q}=\sum_{i=1}^{D} T_{i}
$$

3) Controller parameters: DER and load devices are generally controlled by PI controllers. The equivalent proportional $\left(k_{P}\right)$ and integral $\left(k_{I}\right)$ controller parameters are determined by the PWA values as described by equation 7 .

$$
k_{P, e q}=\sum_{i=1}^{D} k_{P, i} \frac{\left|S_{i}\right|}{\sum_{d=1}^{D}\left|S_{d}\right|}, \quad k_{I, e q}=\sum_{i=1}^{D} k_{I, i} \frac{\left|S_{i}\right|}{\sum_{d=1}^{D}\left|S_{d}\right|}
$$

4) Protection parameters: Mainly three types of internal protection systems are implemented in DER and load devices: overcurrent, under-/overvoltage and under/overfrequency. Overcurrent protection usually limits the peak value of the current and therefore only requires a maximum setting. The setting of the equivalent model is equal to the sum of the overcurrent protection settings of the devices.

The AC under-/overvoltage and under-/overfrequency protection of DERs are dictated by the anti-islanding and faultride-through requirements in the local grid codes. Although this is often equal for all DERs, different requirements may be specified for different DERs (e.g. power rating). This can be solved by classifying DERs in different types.

The DC undervoltage protection of load devices causes temporary or permanent load drop-off. The setting of DC undervoltage protection commonly consists of a minimal threshold value, the setting of the equivalent model is therefore equal to the PWA value of the DC undervoltage protection settings of the devices. 


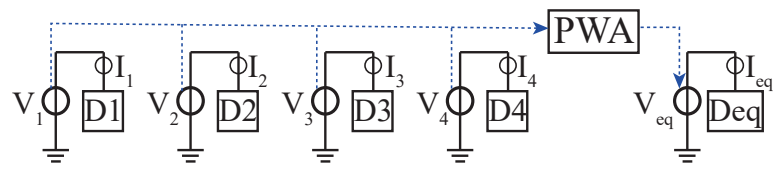

Fig. 5: Setup for validation of device equivalencing. $D_{1}, D_{2}, D_{3}, D_{4}$ : original models, $D_{e q}$ : equivalent model.

TABLE I: Model parameters for each device for the given power rating.

\begin{tabular}{llllll}
\hline Par. & Value & Par. & Value & Par. & Value \\
\hline LEDL & $\mathbf{2 . 4 W}$ & $C_{d c}$ & $840 \mu \mathrm{F}$ & $R_{0}$ & $61.9 \mathrm{~m} \Omega$ \\
$R_{\text {in }}$ & $300 \Omega$ & $R_{s}$ & $0.172 \Omega$ & $L_{b}$ & $21 \mu \mathrm{H}$ \\
$R_{i n 2}$ & $235 k \Omega$ & $R_{r}$ & $0.176 \Omega$ & $C_{d c}$ & $800 \mathrm{uF}$ \\
$C_{i n}$ & $517 \mathrm{nF}$ & $L_{s}$ & $793 \mu \mathrm{H}$ & $L_{1}$ & $10.8 \mathrm{mH}$ \\
$C_{d c}$ & $47 \mu \mathrm{F}$ & $L_{r}$ & $793 \mu \mathrm{H}$ & $L_{2}$ & $477 \mu \mathrm{H}$ \\
VFD & $\mathbf{1 1 k W}$ & $L_{m}$ & $51.4 \mathrm{mH}$ & $C_{1}$ & $10 \mathrm{uF}$ \\
$R_{d c}$ & $0.5 \Omega$ & TPPV & $\mathbf{8 k W}$ & $R_{d}$ & $1.44 \Omega$ \\
$L_{d c}$ & $3 \mathrm{mH}$ & $E_{m}$ & $48 \mathrm{~V}$ & &
\end{tabular}

\section{NUMERICAL VALIDATION}

The methodology described in the last section is validated by comparing the original and equivalent models during large voltage and frequency transients, and by comparing the voltage waveforms during FII in a case study.

\section{A. Devices}

Three types of devices are considered: compact fluorescent lighting (CFL) load, variable frequency drive (VFD) load and three phase photovoltaic (TPPV, $8 \mathrm{kHz}$ switching frequency) DER as shown in Figs. 2, 3 and 4. The electrical parameter values of the models are shown in table I. The CFL has a constant current equivalent resistance $R_{e q i}$ with a drop-off voltage of $35 \mathrm{~V}$. The VFD has a direct torque controller with controller gains $k_{p t}=0.005, k_{i t}=100$ and a speed controller with controller gains $k_{p s}=10, k_{i s}=4$ to drive an $11 \mathrm{~kW}$ symmetrical induction machine modeled in the dq reference frame as described by [15]. The VFD drop-off voltage is $420 \mathrm{~V}$ with a hysteresis of 30V. The TPPV has a synchronous reference frame phase-locked loop (PLL) with controller gains $k_{p p l l}=30.87, k_{i p l l}=1029$ and a current controller in the $\mathrm{dq}$ reference frame with gains $k_{p p i}=1.63, k_{i p i}=204$. The passive anti-islanding protection trips when the voltage $V \leq 0.7 \mathrm{pu}$ for $10 \mathrm{~ms}, V \geq 1.05 \mathrm{pu}$ or $V \leq 0.8 \mathrm{pu}$ for $1.95 \mathrm{~s}$, or if the frequency $f \geq 75 \mathrm{~Hz}$ or $f \leq 25 \mathrm{~Hz}$ for $1 \mathrm{~ms}$ or $f \geq 51 \mathrm{~Hz}$ or $f \leq 48 \mathrm{~Hz}$ for $2 \mathrm{~s}$. The original are scaled to higher power ratings with equal dynamics as described in section II-C.

\section{B. Device equivalencing}

The device equivalencing methodology is validated by determining the normalized mean absolute error (NMAE) of the absorbed/injected current in the setup shown in Fig. 5. The NMAE is determined for CFL, VFD and TPPV by comparing the sum of the current of four scaled models to the current of the equivalent model by using equation 8 . Where $\hat{I}_{n}$ is the nominal peak current, $I_{e q}(t)$ is the current of the equivalent model and $I_{o r}(t)=I_{1}(t)+I_{2}(t)+I_{3}(t)+I_{4}(t)$ is the sum of the current of the original (scaled) models repectively. The
TABLE II: Sensitivity analysis parameter variation in pu.

\begin{tabular}{lllll}
\hline Device & $0.2 \mathrm{pu}$ & $0.6 \mathrm{pu}$ & $1 \mathrm{pu}$ & $1.4 \mathrm{pu}$ \\
\hline 1 & 1.1 & 1.3 & 1.5 & 1.7 \\
2 & 1.05 & 1.15 & 1.25 & 1.35 \\
3 & 0.95 & 0.85 & 0.75 & 0.65 \\
4 & 0.9 & 0.7 & 0.5 & 0.3
\end{tabular}

TABLE III: Sensitivity analysis voltage levels during steady state/voltage transient in pu.

\begin{tabular}{lllll}
\hline Device & $0.1 \mathrm{pu}$ & $0.2 \mathrm{pu}$ & $0.3 \mathrm{pu}$ & $0.4 \mathrm{pu}$ \\
\hline 1 & $1.05 / 0.15$ & $1.1 / 0.2$ & $1.2 / 0.3$ & $1.3 / 0.4$ \\
2 & $1.025 / 0.125$ & $1.05 / 0.15$ & $1.125 / 0.225$ & $1.2 / 0.3$ \\
3 & $0.975 / 0.075$ & $0.95 / 0.05$ & $0.975 / 0.075$ & $1 / 0.1$ \\
4 & $0.95 / 0.05$ & $0.9 / 0$ & $0.9 / 0$ & $0.9 / 0$
\end{tabular}

scaled CFL models have a power rating of $2.7 \mathrm{~kW}, 5.4 \mathrm{~kW}$, $10.8 \mathrm{~kW}$ and $21.6 \mathrm{~kW}$ divided over three phases. The scaled VFD models have a power rating of $11 \mathrm{~kW}, 22 \mathrm{~kW}, 33 \mathrm{~kW}$ and $44 \mathrm{~kW}$. The scaled TPPV models have a power rating of $4 \mathrm{~kW}$, $8 \mathrm{~kW}, 16 \mathrm{~kW}$ and $32 \mathrm{~kW}$. Thus, the equivalent CFL, VFD and TPPV models have a power rating of $40.5 \mathrm{~kW}, 110 \mathrm{~kW}$ and $60 \mathrm{~kW}$ respectively.

$$
e(t)=\frac{1}{\hat{I_{n} T}} \int_{t=0}^{T}\left|I_{e q}(t)-I_{o r}(t)\right| d t
$$

The NMAE is determined over a period of $500 \mathrm{~ms}$ during which a voltage or frequency step change takes place. Voltage transients are performed by step changing the voltage from $1.0 \mathrm{pu}$ to $0.1 \mathrm{pu}$ and back to $1.0 \mathrm{pu}$ after $200 \mathrm{~ms}$. Frequency transients are performed by a step change from $50 \mathrm{~Hz}$ to $20 \mathrm{~Hz}$ and back to $50 \mathrm{~Hz}$ over the same period. Pre- and postdisturbance performance are thus analyzed over $150 \mathrm{~ms}$ before and after the transient. This mimics the temporary voltage and frequency deviations which are expected during the FII transient. The transients are initiated at a phase angle of $90^{\circ}$, where the voltage waveform of phase $a$ is at its peak value.

As devices in a network may have different parameters and the nodes to which the devices are connected may have voltage differences, a sensitivity analysis is performed by varying the parameters and voltage difference between the devices. The difference between the electrical, mechanical and controller parameters of the devices are varied between $0.3 \mathrm{pu}$ and $1.7 \mathrm{pu}$ according to table II (additional to scaling due to the different power ratings). The voltage differences are varied between $0.1 \mathrm{pu}$ and $0.4 \mathrm{pu}$ according to table III. In this scenario, the equivalent model is connected to the PWA of the voltages of devices $1,2,3$ and 4 .

\section{Case study}

A modified version of the CIGRE European LV residential distribution benchmark network is used to validate the load aggregation methodology as shown in Fig. 6. The network contains two three-phase battery energy storage systems (BESS) which are modeled as TPPV normally operating in gridfeeding operation and switch to grid-supporting operation when the anti-islanding detection trips. The grid-feeding and grid-supporting controllers are modeled as described by [16] 


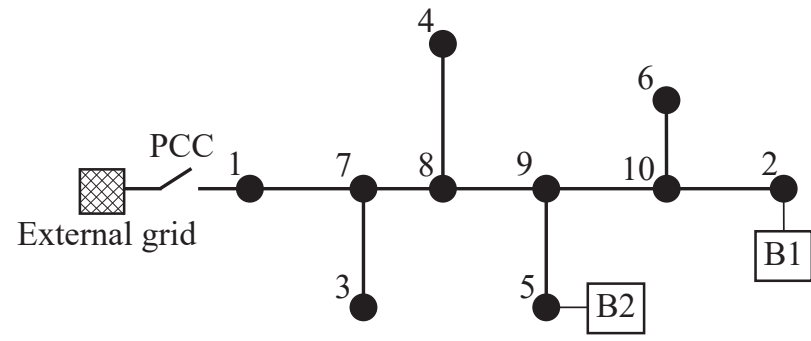

Fig. 6: Modified CIGRE European LV residential distribution benchmark network. B1, B2: battery energy storage systems.

TABLE IV: Power rating and parameter multipliers of grid-feeding DER and load devices in the network. CZ: constant impedance load, PV: grid-feeding photovoltaic DER, Mult.: parameter multiplier of devices connected to node (only used in scenario 2).

\begin{tabular}{llllll}
\hline Node & CFL $(\mathrm{kW})$ & VFD $(\mathrm{kW})$ & CZ $(\mathrm{kW})$ & PV $(\mathrm{kW})$ & Mult. \\
\hline 1 & 2.7 & 22 & 1.25 & - & 0.7 \\
2 & - & 44 & 1.25 & 4 & 0.8 \\
3 & 5.4 & - & 1.25 & 32 & 0.9 \\
4 & 10.8 & - & 2.5 & - & 1.1 \\
5 & - & 33 & 2.5 & 8 & 1.2 \\
6 & 21.6 & - & 1.25 & 16 & 1.3 \\
7 & - & - & 5 & - & - \\
8 & - & - & - & - & - \\
9 & - & - & 2.5 & - & - \\
10 & - & - & - & - & -
\end{tabular}

A three phase fault is simulated in the external grid at $t=0.1 \mathrm{~s}$ by reducing the voltage of the external grid to $0.1 \mathrm{pu}$. At $t=0.15 \mathrm{~s}$ the network is islanded by opening the point of common coupling. After islanding, the islanding detection systems of the BESS will trip and switch the BESS from gridfeeding to grid-supporting operation.

The network nodes are classified in the following way: nodes 1, 2 and 5 are boundary nodes, nodes 3, 4 and 6 are device nodes, nodes 7 and 9 are interior nodes, and nodes 8 and 10 are empty nodes. The grid-feeding DER and load devices at each node are shown in table IV. The constant impedance loads are modeled as parallel RL loads with a power factor of 0.95 . The network consist of $240 \mathrm{~mm}^{2}$ AL cables modeled as series RL branches with a resistance and reactance of $0.15 \Omega / \mathrm{km}$ and $0.071 \Omega / \mathrm{km}$ respectively. The parasitic cable capacitance is neglected due to the short length. The network cables lengths are shown in table V.

Three scenarios are analyzed to evaluate the performance of the aggregation methodology in different conditions. Scenario 1 is the baseline where the parameters of the grid-feeding DER and load models of the same type are scaled from the models described in III-A based on power rating. In scenario 2 , the electrical (impedance), mechanical (inertia and friction) and controller (controller gains) parameters of the grid-feeding DER and load models are multiplied by the corresponding multipliers shown in table IV. This scenario emulates a case in which DERs and loads have different parameters. In scenario 3 , the network impedance is five times larger which emulates a network with larger voltage differences between DERs and loads.
TABLE V: Network cable lengths.

\begin{tabular}{cccccccccc}
\hline & $1-7$ & $2-10$ & $3-7$ & $4-8$ & $5-9$ & $6-10$ & $7-8$ & $8-9$ & $9-10$ \\
\hline Length (m) & 70 & 70 & 30 & 135 & 30 & 30 & 35 & 70 & 105
\end{tabular}

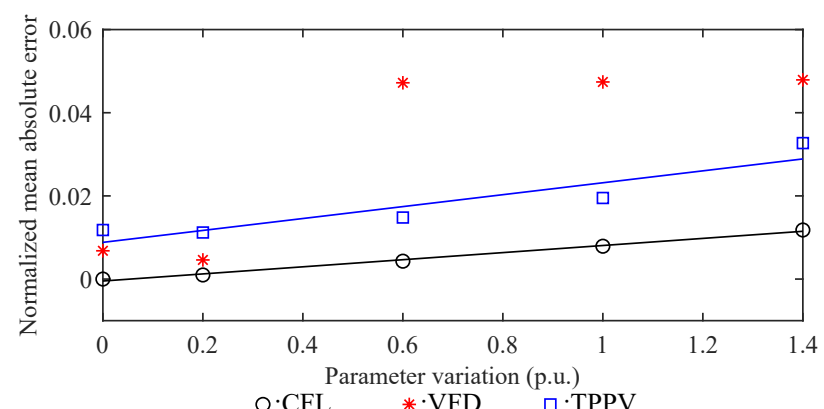

Fig. 7: Normalized mean absolute error of the current of the equivalent CFL, VFD and TPPV models with different parameter variations in case of a voltage transient.

\section{RESUlts}

\section{A. Device equivalencing}

As discussed before, large differences between the parameters of devices and the voltages of different network nodes may impact the accuracy of the aggregated model. The parameter and node voltage variations are simulated as described in section II-C. The NMAE of the equivalent CFL, VFD and TPPV models with different parameter variations in case of a voltage and frequency transients is shown in Figs. 7 and 8 respectively. The NMAE is below $0.1 \mathrm{pu}$ in almost all cases which indicates that the equivalent models accurately represent the dynamics of the original models and that a larger variation in parameters generally leads to an increasing error. The impact of parameter variations is most significant in case of VFDs, however even with a variation of 1.4 p.u. the maximum NMAE is smaller than 0.05. The NMAE does not increase linearly with the parameter variation due to nonlinear effects. For example, when the parameter variation is $0.6 \mathrm{pu}$ or larger the smallest VFD drops off during a voltage transient, while the largest VFDs and the equivalent model remain operational.

The NMAE of the current absorbed injected by the equivalent CFL, VFD and TPPV models with different node voltages in case of a voltage and frequency transients is shown in Figs. 9 and 10 respectively. The NMAE increases when the node voltage variation increases in three cases, while the NMAE remains approximatly constant in three other cases. Node voltage variation mostly impacts the accuracy of the equivalent TPPV due to PLL tracking issues during the frequency transients. The equivalent model of the TPPV is therefore considered accurate during frequency transients when the voltage variation is smaller than $0.3 \mathrm{pu}$.

\section{B. Case Study}

The voltage waveforms at node 2 in the original and aggregated networks are shown in Figs. 11, 12 and 13 for scenario 1,2 and 3 respectively. The dynamics during the FII transient are similar in all scenarios. At $t=0.1 \mathrm{~s}$ the 


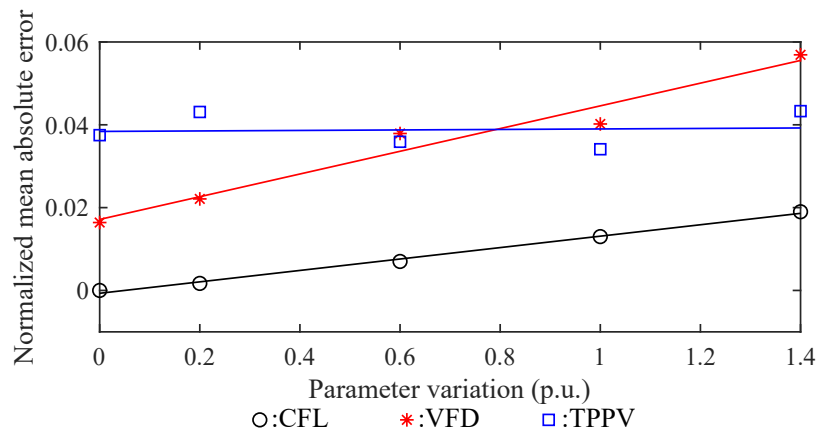

Fig. 8: Normalized mean absolute error of the current of the equivalent CFL, VFD and TPPV models with different parameter variations in case of a frequency transient.

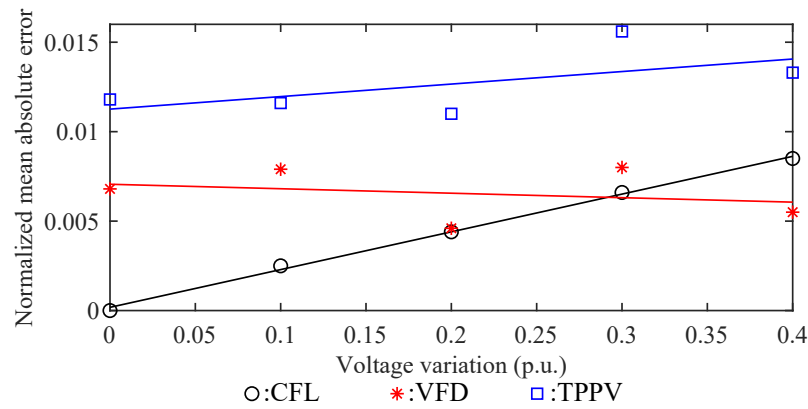

Fig. 9: Normalized mean absolute error of the current of the equivalent CFL, VFD and TPPV models with different voltage variations in case of a voltage transient.

fault causes the voltage to decrease significantly. When the network is islanded at $t=0.15 \mathrm{~s}$ the voltage increases while the frequency slightly decreases. Islanding is detected by the BESS around $t=0.21 \mathrm{~s}$ in all scenarios, recovering the voltage and frequency to near nominal values. The voltage waveforms remain partly distorted after control-mode switching due to the nonsinusoidal current waveforms of power electronic loads.

As shown in Figs. 11, 12 and 13, the original and aggregated voltage waveforms are very similar during and after the FII transient. Slight differences are visible during islanding before the BESS switch to grid-feeding control. The results from scenario 2 show that parameter differences between models impact the accuracy of the aggregated model. The increased network impedance has no significant negative effect on the accuracy of the aggregated model.

The simulations are performed in Matlab/Simulink using the ode23tb solver with a maximum step size of $1 \mu \mathrm{s}$ on a PC with an Intel i7-4700MQ processor and 8GB of RAM. The computation time of the three scenarios is averaged. The average computation time to simulate a single scenario is 36837 seconds using the original model and 4909 seconds using the aggregated model, resulting in a reduction of $87 \%$.

\section{Discussion}

The results indicate that the proposed methodology accurately aggregates component-based grid-feeding DER and load models which greatly reduces the computational burden of FII simulations. The error of the dynamic equivalent models

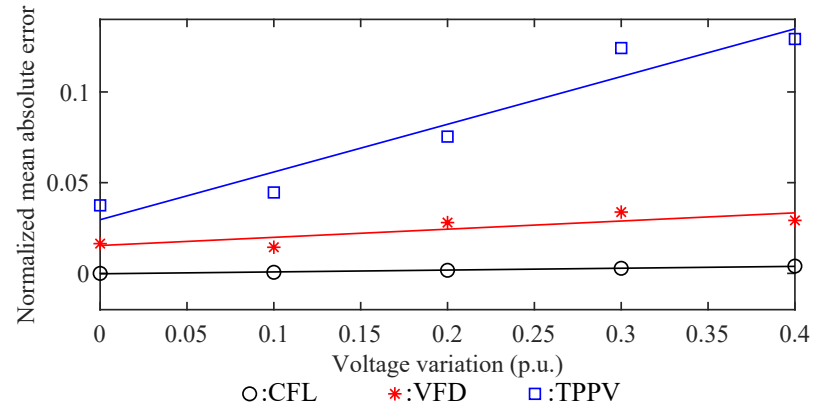

Fig. 10: Normalized mean absolute error of the current of the equivalent CFL, VFD and TPPV models with different voltage variations in case of a frequency transient.

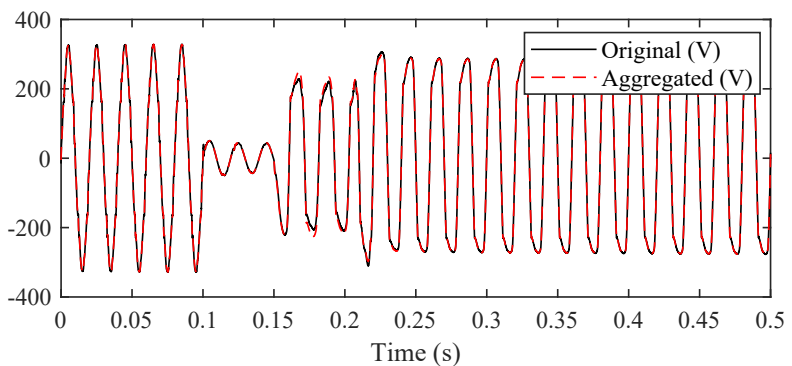

Fig. 11: Comparison of the voltage at node 2 in the original network and the aggregated network in scenario 1 .

developed in section II-C increases when the devices of the same classification have a larger variation in parameters and when the devices are connected to nodes with different voltages. It should be noted that the device equivalencing negates possible interactions between devices of the same type. However the impact on the simulation results is limited since these interactions mainly occur between droop controlled gridsupporting DERs [6], which are preserved in the proposed methodology. Additionally, a small-signal stability analysis approach is often preferred to analyze the high frequency (voltage and current controller) interactions in microgrids.

The reduction in computational burden enables periodical (bi-hourly) analysis of the voltage and frequency stability analysis during and right after FII, even on a laptop computer.

Detailed component-based DER and load models are required to develop the aggregated model. This information may not be available to the microgrid operator, which requires the load to be identified. A suitable methodology to identify load devices based on aggregated measurements is proposed by [17]. Alternatively, smart meters can be utilized to identify load devices as described by [18].

The accuracy of the aggregated model is mainly impacted by parameter variations between different DER and load models of the same type. This is evident as models with very different dynamics are difficult to represent with an equivalent model. This can be solved by increasing the number of grid-feeding DER and load classifications, however this also increases the computation time as this results in additional equivalent models. Optimization of the number of DER and load type classifications should therefore be treated by future research. 


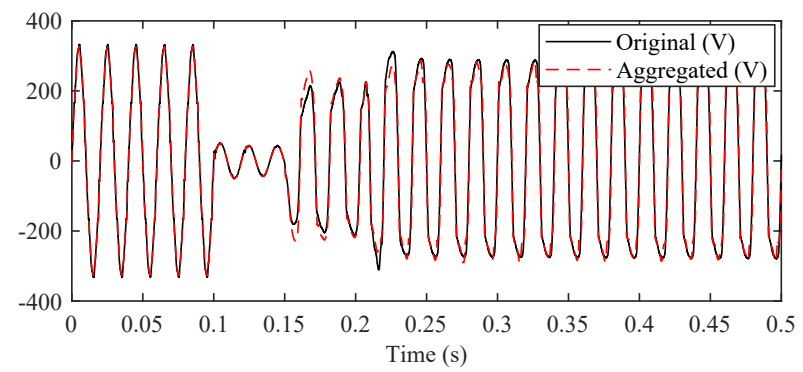

Fig. 12: Comparison of the voltage at node 2 in the original network and the aggregated network in scenario 2 .

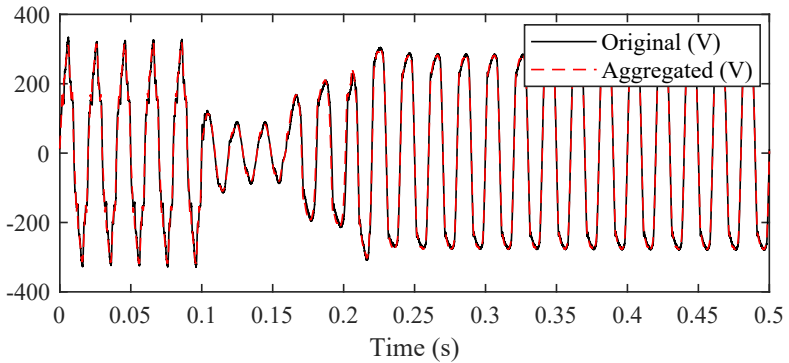

Fig. 13: Comparison of the voltage at node 2 in the original network and the aggregated network in scenario 3 .

Large voltage differences between network nodes also impact the accuracy of the aggregated model, however this error is less significant since the voltage differences in microgrids are small, even with high network impedance.

There are many different types of DERs and loads connected to distribution networks [19]. Additionally, these devices can have different dynamics e.g. due to the type of control [20], [21], phase locked loop [22], anti-islanding detection [23], power factor correction [19] and mechanical load [24]. Several component-based DER and load models have been proposed in the literature [7], [8], however more DER and load models should be developed and validated in future research to enable analysis of microgrids with different types of DERs and loads.

\section{CONCLUSION}

This paper describes a methodology to aggregate gridfeeding DER and load models in microgrids to reduce computational burden while enabling accurate voltage and frequency stability analysis during and right after FII. The comparison of original and equivalent DER and load models, and the case study show that the proposed methodology constructs accurate aggregated models. In the case study the computation time of the aggregated model is reduced by $87 \%$ while a small error is introduced, enabling accurate periodical stability analysis.

Future research should treat the optimal classification of load types before equivalencing, and the development and validation of more component-based models.

\section{REFERENCES}

[1] Y. Wang, C. Chen, J. Wang, and R. Baldick, "Research on Resilience of Power Systems under Natural Disasters - A Review," IEEE Transactions on Power Systems, vol. 31, no. 2, pp. 1604-1613, 2016.
[2] Z. Wang and J. Wang, "Self-healing Resilient Distribution Systems based on Sectionlization into Microgrids," IEEE Transactions Power Systems, vol. 30, no. 6, pp. 3139-3149, 2015.

[3] C. Chen, J. Wang, F. Qiu, and D. Zhao, "Resilient Distribution System by Microgrids Formation after Natural Disasters," IEEE Transactions on Smart Grid, vol. 7, no. 2, pp. 958-966, 2016.

[4] D. Dong, B. Wen, D. Boroyevich, P. Mattavelli, and Y. Xue, "Analysis of Phase-Locked Loop Low-Frequency Stability in Three-Phase Grid-Connected Power Converters Considering Impedance Interactions," IEEE Transactions on Industrial Electronics, vol. 62, no. 1, pp. 310-321, jan 2015.

[5] W. Zheng, P. Crossley, B. Xu, and H. Qi, "Transient stability of a distribution subsystem during fault-initiated switching to islanded operation," International Journal of Electrical Power and Energy Systems, vol. 97, no. August 2017, pp. 418-427, 2018.

[6] IEEE PES Power System Dynamic Performance Committee IEEE and IEEE PES Task Force on Microgrid Stability Analysis and Modeling, "Microgrid Stability Definitions, Analysis and Modeling," Tech. Rep. April, 2018.

[7] JOINT WORKING GROUP C4/C6.35/CIRED, "Modelling of InverterBased Generation for Power System Dynamic Studies," CIRED, Tech. Rep. May, 2018.

[8] Cirgré Working Group C4.605, "Modelling and Aggregation of Loads in Flexible Power Networks," Cigre, Tech. Rep. February, 2014.

[9] D. C. Franklin and A. Morelato, "Improving dynamic aggregation of induction motor models," IEEE Transactions on Power Systems, vol. 9, no. 4, pp. 1934-1941, 1994.

[10] F. Milano and K. Srivastava, "Dynamic REI equivalents for short circuit and transient stability analyses," Electric Power Systems Research, vol. 79, no. 6, pp. 878-887, 2009.

[11] X. Liang and C. Y. Chung, "Bus-Split Algorithm for Aggregation of Induction Motors and Synchronous Motors in Dynamic Load Modeling," IEEE Transactions on Industry Applications, vol. 50, no. 3, pp. 21152126, may 2014.

[12] A. J. Collin, S. Member, J. L. Acosta, S. Member, B. P. Hayes, and S. Member, "Component-based Aggregate Load Models for Combined Power Flow and Harmonic Analysis," in 7th Mediterranean Conference and Exhibition on Power Generation, Transmission, Distribution and Energy Conversion, no. November, 2010.

[13] X. Xu, J. Gunda, and D. Fang, "Modelling and Aggregation of LED Lamps for Network Harmonic Analysis," in 2018 Power Systems Computation Conference (PSCC). IEEE, jun 2018, pp. 1-7.

[14] L. Luo and S. V. Dhople, "Spatiotemporal model reduction of inverterbased islanded microgrids," IEEE Transactions on Energy Conversion, vol. 29 , no. 4 , pp. 823-832, 2014.

[15] P. Krause, O. Wasynczuk, and S. Sudhoff, Analysis of Electric Machinery and Drive Systems. IEEE Press, 2002.

[16] J. Rocabert, A. Luna, F. Blaabjerg, and I. Paper, "Control of Power Converters in AC Microgrids.pdf," IEEE Transactions on Power Electronics, vol. 27, no. 11, pp. 4734-4749, 2012.

[17] X. Wu, X. Han, L. Liu, and B. Qi, "A load identification algorithm of frequency domain filtering under current underdetermined separation," IEEE Access, vol. 6, pp. 37 094-37 107, 2018.

[18] H. Ahmadi and J. R. Marti, "Load Decomposition at Smart Meters Level Using Eigenloads Approach," IEEE Transactions on Power Systems, vol. 30, no. 6, pp. 3425-3436, 2015.

[19] A. Collin, "Advanced Load Modelling for Power System Studies," Ph.D. dissertation, The University of Edinburgh, 2013.

[20] J. Rocabert, A. Luna, F. Blaabjerg, and I. Paper, "Control of Power Converters in AC Microgrids," IEEE Transactions on Power Electronics, vol. 27, no. 11, pp. 4734-4749, 2012.

[21] G. Buja and M. Kazmierkowski, "Direct Torque Control of PWM Inverter-Fed AC Motors-A Survey," IEEE Transactions on Industrial Electronics, vol. 51, no. 4, pp. 744-757, aug 2004.

[22] S. Golestan, J. M. Guerrero, and J. C. Vasquez, "Three-Phase PLLs: A Review of Recent Advances," IEEE Transactions on Power Electronics, vol. 32, no. 3, pp. 1894-1907, mar 2017.

[23] C. Li, C. Cao, Y. Cao, Y. Kuang, L. Zeng, and B. Fang, "A review of islanding detection methods for microgrid," Renewable and Sustainable Energy Reviews, vol. 35, pp. 211-220, 2014.

[24] C. Cresswell, S. Djoki, and M. Ieee, "Representation of Directly Connected and Drive-controlled Induction Motors. Part 2: Three-phase Load Models," in Proceedings of the 2008 International Conference on Electrical Machines, 2008, pp. 1-6. 